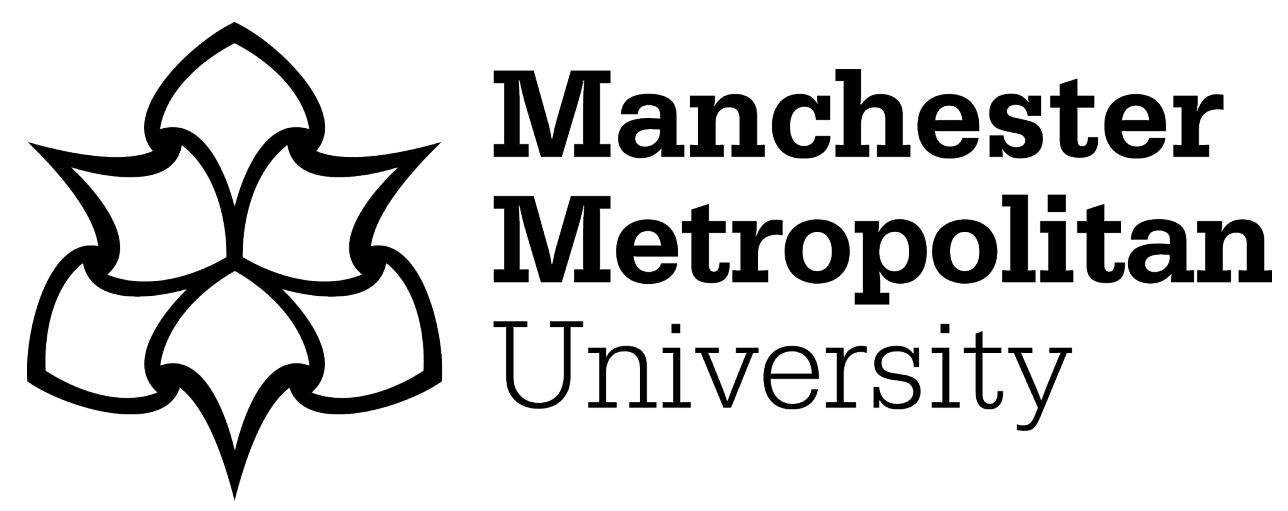

Jogunola, Olamide ORCID logoORCID: https://orcid.org/0000-0002-27019524, Tsado, Yakubu, Adebisi, Bamidele and Hammoudeh, Mohammad (2022) VirtElect: A Peer-to-Peer Trading Platform for Local Energy Transactions. IEEE Internet of Things Journal, 9 (8). pp. 6121-6133. ISSN 23274662

Downloaded from: https://e-space.mmu.ac.uk/628359/

Version: Accepted Version

Publisher: Institute of Electrical and Electronics Engineers (IEEE)

DOI: https://doi.org/10.1109/jiot.2021.3109613

Please cite the published version 


\title{
VirtElect: A Peer-to-Peer Trading Platform for Local Energy Transactions
}

\author{
Olamide Jogunola, Yakubu Tsado, Bamidele Adebisi and Mohammad Hammoudeh
}

\begin{abstract}
An average UK electricity bill is made up of at least $60 \%$ service charge, with approximately $22 \%$ related to network characteristics including distance charge. This makes distance and network constraints important factors in matching prosumers on any peer-to-peer energy trading platform as assessed in this paper. To realise that, A platform - VirtElect, based on a double auction market is developed to support the matching interaction between prosumers. Case studies based on real microgrid data are used to verify the performance of the platform in demonstrating the potential of local energy consumption. Results show that it is possible to balance local energy generation and consumption, with little or no interaction with the utility grid. We also show that local energy trading is not only beneficial to the environment but also leads to a significant amount of cost savings of up to $45 \%$, depending on the number of participants and their ratios on the platform.
\end{abstract}

Index Terms-Peer-to-peer energy trading, local energy consumption, distance constraints, utility maximisation, network constraints, auction-based market.

\section{INTRODUCTION}

Peer-to-peer energy trading and sharing (P2P-ETS) platform can provide a market mechanism facilitating mutually beneficial energy transactions between traditional energy consumers that have become 'prosumers' who can both generate and consume their energy. P2P-ETS platform can be implemented to enable the exchange of information and energy among energy traders of different sizes, including prosumers, residential houses, or local distribution networks [1]-[3]. Besides, the platform can assists the system operators to monitor and control the energy integration to the distribution network, for instance, balancing energy supplies and demands.

As such, several pilot energy transaction projects and platforms are currently being trialed in several countries. These include the Piclo in the UK [4], Vandebron in the Netherlands [5], SonnenCommunity in Germany [6], and the Brooklyn microgrid in the US [7]. Some of these projects fit into four P2P-ETS platform models [8]; the retail supplier platform, vendor platform, community microgrid platform, and blockchain platform models.

The Piclo and Vandebron projects utilise online platforms that allow prosumers to select and track the source of the energy they buy. They are representative examples of the retail supplier platform model as they allow suppliers to benefit

The authors are with Manchester Metropolitan University, Manchester M1 5GD, UK. \{o.jogunola, y.tsado, b.adebisi, m.hammoudeh\}@mmu.ac.uk This work was supported by ENERGY-IQ, a UK-Canada Power Forward Smart Grid Demonstrator project funded by The Department for Business, Energy and Industrial Strategy (BEIS) under Grant number:7454460.

Copyright (c) 20xx IEEE. Personal use of this material is permitted. However, permission to use this material for any other purposes must be obtained from the IEEE by sending a request to pubs-permissions@ieee.org. by gaining a better awareness of their customers and also obtain more value from their distributed energy resources (DER) [1]. SonnenCommunity project is similar to Piclo and Vandebron but with more utilisation of storage systems for battery owners [6]. SonnenCommunity is an example of the vendor platform model that allows the exchange of energy between producers and consumers where the owner of the platform gets a commission for every sale. The Brooklyn P2PETS platform is a network of Brooklyn residents and business owners to allow social factor inclusion by encouraging generous prosumers with surplus energy to donate energy to low-income households [9]. The Brooklyn microgrid uses a blockchain model to provide secure decentralised protocols for managing and executing transactions through its smart contracts, thereby classified as a community and the blockchain P2P-ETS platform models.

However, the type of trading rules and controls defined by these platforms have a significant influence on the decisions made by the prosumers. Setting preferences and autonomy to decide the terms of trade are also additional incentives for participating in P2P-ETS platforms [10]. Similarly, to aid in local energy consumption thereby reducing the carbon footprint, distance as a function of the physical location of prosumers is an important factor in matching prosumers on any energy trading platform. For instance, at least $20 \%$ of an electricity bill is network cost including distance charge [11]. Besides, other $\mathrm{P} 2 \mathrm{P}$ constraints such as price and product divisibility, implementability and network constraints consisting of voltage variation and line losses should be jointly integrated into the energy trading models and platforms as these constraints have their impact on the economic and environmental benefit derived by the grid, prosumers or the community at large.

Compared with the existing P2P-ETS platform designs and models, that considered one or two constraints, the main contributions of this work can be summarised as follows:

- a P2P-ETS platform to support the matching interaction between energy traders is presented. The platform is designed for an implementable hybrid market within the current distribution network integrating diverse solutions for different technical aspects of $\mathrm{P} 2 \mathrm{P}$ markets to improve the economic benefit of the prosumers by maximising their social welfare and unitary benefit;

- as environmental emission is mostly determined by the distance energy travels from producers to consumers, as well as a factor in determining the amount paid for energy consumption, distance and network constraints violation charges are implemented on the platform to encourage energy trading with closest neighbours. This highlighted the benefits of local energy consumption to the community and environment; 
- an evaluation of the platform was carried out to show the extent to which the P2P-ETS can benefit prosumers in the network. This is achieved by varying their ratios to determine the optimal mix for maximum benefit.

The remaining sections are as follows. A literature review of P2P energy trading models is discussed in Section II. The development of the energy trading platform 'VirtElect' is introduced in Section III, the market bids and matching algorithm is presented in Section IV. The performance evaluation of the platform is discussed in Section V. Section VI concludes the paper and discusses future work.

\section{ReView of P2P ENergy Trading Models}

Recently, the development of a market framework has been the focus on P2P-ETS where buyers and sellers cooperate to determine the ultimate energy trading contracts [12]-[14]. This development has been shown to reduce battery capacity and energy losses [15]. The related effort focused on the computational properties of the negotiation algorithms [16], the optimised scheduling of energy storage system (ESS) using automated negotiations [17], multi-commodity optimisation of energy traders' resources [18] and prosumers' behavioural patterns based on their bidding strategies. Other market clearing algorithms include the use of distributed optimisation methods [19], consensus-based optimisation [20], dual-based prices like alternating direction method of multipliers (ADMM) [21], reinforcement learning [22] and double-auction for matching prosumers in the market.

In the double-auction market, sellers and buyers report their reservation prices and bids for the efficient operation of the market. This technique has been reported in the literature to achieve the objective of balancing local generation and demand, improves prosumers engagement, and offloading demands at peak time [23]-[27]. For instance, a blockchainbased distributed double auction trade mechanism for energy trading platform is presented in [27] using a co-simulation to interface the energy trading platform and the distribution network layer. This is to assess the impact of P2P trading on the distribution network. Their result suggests that a moderate level of P2P trade does not have significant impacts on network operational performance. Similarly, [28] adopted a sensitivity analysis methodology for the same objective as well as to guarantee energy exchange that does not violate network constraints. A consortium blockchain-based double auction mechanism is proposed in [23] for protecting privacy while trading energy. Also, an iterative double auction mechanism is proposed to solve the electricity pricing and traded quantity in balancing local energy generation and supply. The result showed that the double auction mechanism achieves social welfare maximisation while preserving the privacy of the peers. A similar objective is achieved in [25] for an optimal bidding strategy using a double auction among residential houses. Specifically, utilising the responsive household appliances and ESS, day-ahead and intraday energy management models for residential houses are established for an hour-ahead intraday energy transaction. The authors concluded that the residential demand response schemes and intraday P2P-ETS are effective in managing the uncertainties of load demand and renewable generation.

To reduce peak demand and improve users' participation in local energy trading, the authors of [24] and [26] investigated a data-driven prediction-integration model and Nash bargaining model respectively in their designs of double auction mechanisms. Particularly, [26] designed an incentive mechanism for their energy sharing model to ensure fair benefits to DERS' owners based on their contributions using Pennsylvania-New Jersey-Maryland's capacity market multi-auction structure. Furthermore, Utilising the Rubinstein alternating offers protocol, [29] proposed a bilateral negotiation framework for energy trading in different periods throughout the day. With the use of different negotiation concession algorithms, the prosumers were able to increase their revenue and reduce their costs. These studies, however, did not integrate distance and divisibility constraints between the trading entities to assess their impact on the achieved objectives.

In contrast, the work in [20] proposes multi-bilateral trading with product differentiation based on consumer preferences, i.e., distance. Their results suggest an increased trading cost and a reduction in the maximum power that flows through prosumers on different buses compared to a case without product differentiation. Similarly, [30] proposed a stable matching mechanism and a continuous double auction-based mechanism for P2P trading while accounting for the electrical distance to prioritise trading between peers. The work in [31] proposes exogenous cost allocation including zonal fees and electrical distance fees for cost recovery for the system operator. The exogenous parameter is modelled as an additional cost that might restrict the participation of traders in the market.

While these theoretical studies [20], [30], [31] assess distance as a product differentiation parameter for a decentralised market, here we are assessing its impact in a hybrid market implemented in an energy trading platform. Against this background, this paper advances the current state-of-the-art by considering the distance and network constraints as a major factor in matching peers for energy trading. In addition, to increase profit maximisation, the quantity of energy supplied and demanded can be divided and satisfied by one or more prosumers. This energy and price divisibility feature enables the sale/purchase of different quantities at different prices, offering more control and increase savings. These two factors are achieved by developing a P2P-ETS platform to support the pairing interaction among energy traders. Comparative analysis of this study and other P2P-ETS models is presented in Table I.

\section{The Proposed P2P-ETS Platform Design}

To enable information exchange among prosumers and to facilitate the monitoring of the distribution network by the utility operators, a P2P-ETS platform is actively needed that incorporates a variety of energy traders. Fig. 1 illustrates interactions on the proposed platform - VirtElect, while the following subsections discuss the platform in detail. 
TABLE I: Comparative analysis of representative models of P2P energy trading with this study

\begin{tabular}{|c|c|c|c|c|c|c|c|c|}
\hline \multirow{2}{*}{$\begin{array}{l}\text { P2P-ETS } \\
\text { models }\end{array}$} & \multirow[t]{2}{*}{ Ref. } & \multirow[t]{2}{*}{ Year } & \multirow[t]{2}{*}{ Objective } & \multicolumn{5}{|c|}{ P2P-ETS constraints } \\
\hline & & & & Distance & Divisibility & $\begin{array}{l}\text { Network } \\
\text { constraints }\end{array}$ & $\begin{array}{l}\text { Hybrid } \\
\text { market }\end{array}$ & Platform \\
\hline \multirow[t]{5}{*}{$\begin{array}{l}\text { Constrained } \\
\text { optimisation }\end{array}$} & [12] & 2020 & $\begin{array}{l}\text { A decentralized P2P energy trading scheme } \\
\text { for electricity markets with high penetration } \\
\text { of DERs }\end{array}$ & $\times$ & $\sqrt{ }$ & $\sqrt{ }$ & $x$ & $x$ \\
\hline & {$[32]$} & 2020 & $\begin{array}{l}\text { A hybrid energy trading scheme for different } \\
\text { markets to incorporate prosumers' prefer- } \\
\text { ences }\end{array}$ & $\times$ & $x$ & $\sqrt{ }$ & $\sqrt{ }$ & $x$ \\
\hline & [31] & 2019 & $\begin{array}{l}\text { An exogenous cost allocation framework in- } \\
\text { cluding zonal fees and electrical distance } \\
\text { fees in P2P electricity market. }\end{array}$ & $\sqrt{ }$ & $\times$ & $\sqrt{ }$ & $x$ & $x$ \\
\hline & [33] & 2021 & $\begin{array}{l}\text { A distributed pricing strategy for P2P trans- } \\
\text { active energy systems considering physical } \\
\text { network constraints. }\end{array}$ & $\sqrt{ }$ & $\sqrt{ }$ & $\sqrt{ }$ & $x$ & $x$ \\
\hline & {$[20]$} & 2019 & $\begin{array}{l}\text { A multi-bilateral economic dispatch and } \\
\text { trading with product differentiation based on } \\
\text { consumer preferences }\end{array}$ & $\sqrt{ }$ & $\sqrt{ }$ & $x$ & $x$ & $x$ \\
\hline \multirow[t]{2}{*}{ Game theory } & [34] & 2019 & $\begin{array}{l}\text { A game-theoretic coalition framework to } \\
\text { incentivise prosumers' participation in } \mathrm{P} 2 \mathrm{P} \\
\text { energy trading }\end{array}$ & $\sqrt{ }$ & $x$ & $\sqrt{ }$ & $x$ & $\times$ \\
\hline & [1] & 2018 & $\begin{array}{l}\text { A P2P energy trading platform for a grid- } \\
\text { connected low voltage microgrid with trad- } \\
\text { ing simulated using game theory. }\end{array}$ & $\times$ & $x$ & $\sqrt{ }$ & $x$ & $\sqrt{ }$ \\
\hline \multirow{2}{*}{ Blockchain } & [27] & 2020 & $\begin{array}{l}\text { P2P energy trading assessing the impact on } \\
\text { the distribution network }\end{array}$ & $\times$ & $x$ & $\sqrt{ }$ & $x$ & $\sqrt{ }$ \\
\hline & {$[35]$} & 2020 & $\begin{array}{l}\text { A blockchain-based hybrid energy trading } \\
\text { market to reduce costs and peak to average } \\
\text { ratio of electricity }\end{array}$ & $\sqrt{ }$ & $\times$ & $x$ & $\sqrt{ }$ & $x$ \\
\hline \multirow[t]{3}{*}{ Auction theory } & [28] & 2019 & $\begin{array}{l}\text { P2P energy trading under network con- } \\
\text { straints }\end{array}$ & $\times$ & $x$ & $\sqrt{ }$ & $x$ & $x$ \\
\hline & [29] & 2020 & $\begin{array}{l}\text { An automated negotiation framework for en- } \\
\text { ergy trading }\end{array}$ & $x$ & $\times$ & $\sqrt{ }$ & $x$ & $x$ \\
\hline & {$[30]$} & 2021 & Electrical-driven P2P energy trading & $\sqrt{ }$ & $\times$ & $\sqrt{ }$ & $\times$ & $\times$ \\
\hline This study & & 2021 & $\begin{array}{l}\text { A double-auction trading platform for P2P- } \\
\text { ETS assessing the impact of distance includ- } \\
\text { ing violation to network constraints }\end{array}$ & $\sqrt{ }$ & $\sqrt{ }$ & $\sqrt{ }$ & $\sqrt{ }$ & $\sqrt{ }$ \\
\hline
\end{tabular}

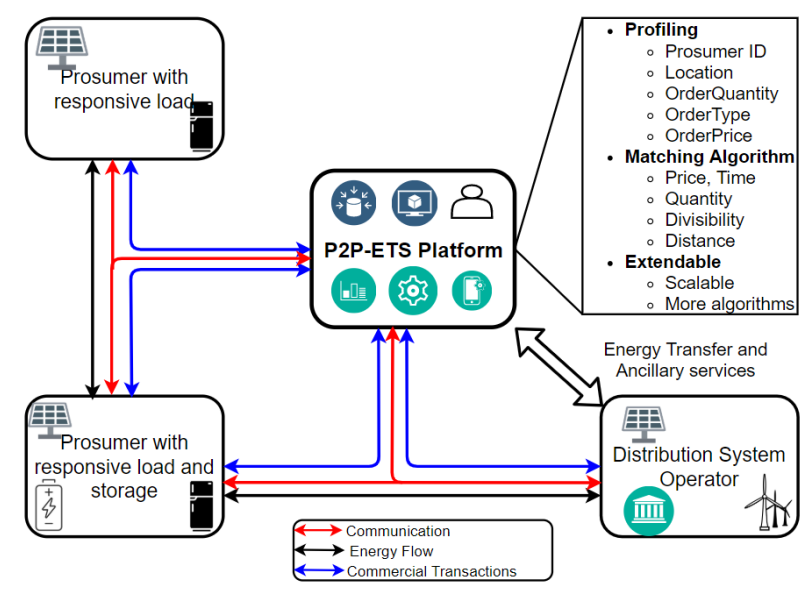

Fig. 1: Interactions of prosumers on the proposed P2P-ETS.

\section{A. P2P-ETS Trading Architecture}

P2P-ETS systems can be organised in three fashions, a centralised, decentralised, and a hybrid of both [36]. VirtElect utilises a centralised auction-based market clearing system that is well suited for the current business structure in energy trading. The architecture can also be expanded to a decentralised or a hierarchical/decentralised architecture to serve power industries where multiple communities coexist in a large utility area. $V$ irtElect is a python programming-based P2P-ETS platform that manages local energy transactions in power networks. It acts as the auctioneer with a central market clearing system by only taking in data and providing an intelligent interface for the prosumers, while communication among the prosumers is decentralised. The energy consumption and generation of each prosumer are recorded by their smart meters which serve as the trading agent. The smart meters also facilitate communication with the platform. The VirtElect supports P2P energy trading in a grid-connected microgrid and it consists of consumers, prosumers, and the distribution system operator (DSO), which is also grouped as an energy prosumer on the platform. The DSO is an integral part of the platform that delivers energy to the appropriate prosumer, whilst ensuring network constraints are not violated. 
The electricity grid is made up of the coexistence of multiple communities distributed across different feeders in several locations illustrated in Fig. 2. On the one hand, in a community along the same feeder, trading and sharing within that region will be among prosumers near one another. On the other hand, trading and sharing between prosumers on different feeders will attract more power losses as a result of long distance travelled across substations and cable lines. The following are some considerations that will be taken into account during P2P energy transactions:

- Consumers with no DER can participate and are eligible to only purchase energy.

- Prosumers with DER are eligible to purchase and sell energy.

- The DSO can also buy or sell energy.

- Prosumers with no physical connection to the grid are not eligible to participate in the transaction,

- Regulatory criteria such as minimum electricity capacity and network constraints are integrated to avoid violation or to assign charges as applicable.

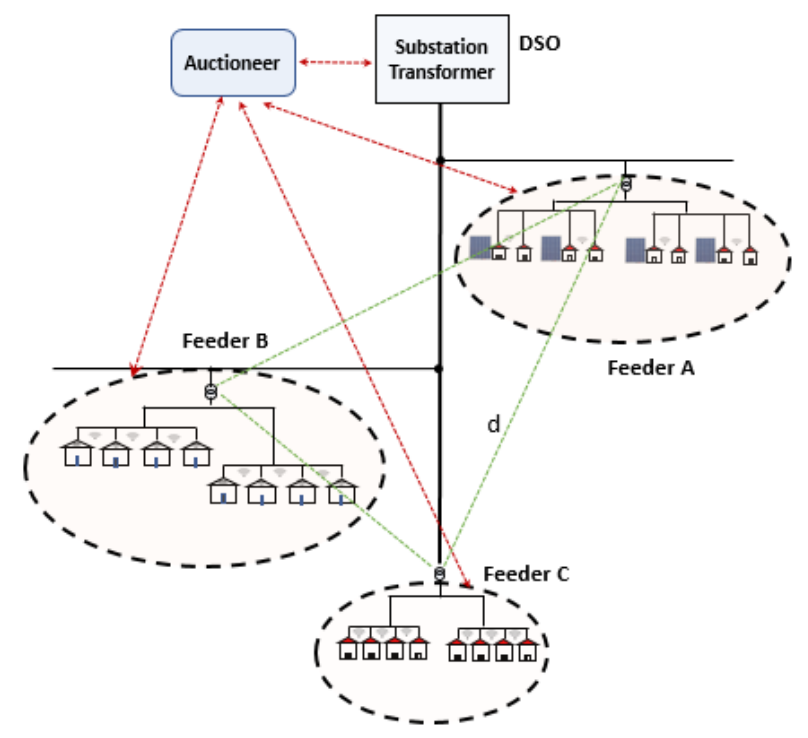

Fig. 2: Local energy consumption, distance charge (adapted from [36]).

\section{B. The Platform (VirtElect) Functions}

The profiling of each prosumer detailing their preferences including energy price, quantity, and location is stored on VirtElect. VirtElect allows the prosumers to place orders for day-ahead energy delivery or intraday trading, based on flexibility and offer prices, with sellers able to respond with when they are available and what services they can provide. There are two predominant forms of intraday trading: discrete auctions and continuous trading. Auction-based intraday markets are cleared at discrete times, while the continuous intraday market is closer to real-time trading as it involves continuous trading throughout the day. Both forms of intraday trading can be adopted with the current methodology of the study by changing the market clearing frequency. The bid information submitted along with the distance constraints of the prosumers, are all taken into consideration before the matching result for the bids and offers is delivered. It is the responsibility of the prosumers to ensure the orders submitted reflect their energy profile needs as the market mechanism only utilises the submitted orders for matching and trading purposes to deter compromising their privacy. The mismatch between the demand forecasting result and the actual demand values in real-time is beyond the scope of this work. Sellers who have some price flexibility will not have any visibility of the buyers' price, so as not to influence their offer prices. Such a system creates market drivers which can bring costs down. A P2P order will contain the following:

- ProsumerID: A unique number assigned to each prosumer.

- OrderID: A unique number assigned to each order placed by prosumers.

- OrderAction: Buy or sell (bid or offer).

- OrderQuantity: Amount of energy (in kWh) to be traded.

- OrderPrice: Bid price or offer price.

- Prosumer role at time $t$ : Indicates the role of a prosumer, either a consumer or a producer at a particular time $t$.

\section{Network Constraints}

Energy transactions consider both the monetary transaction and physical electrical power transport through the grid. As a result of the integration of DER to the electrical power network from multiple prosumers, the physical transportation of electrical power is subject to physical network constraints which must not be violated through extensive transactions in the energy network. Studies on physical network constraints and how it impacts energy transactions in the grid network have been carried out. In [36], a platform that considers the system's ability to accommodate DER was implemented by measuring the PV hosting capacity of an electrical power system. They defined a violation as either overloading of power lines and transformers or a voltage set point greater than 1.04 times the nominal voltage. The impact of the transaction on voltage and network capacity was presented in [28] to guarantee an exchange of energy that does not violate network constraints. Other sample models that consider the effect of network constraints like voltage variations, utilisation rate of the lines for congestion control, and system losses, are presented in [31], [37]-[40]. To evaluate the impact of these constraints within this study, the following are defined.

1) Voltage Variations: a transaction that causes voltage variation in the network will not be allowed to proceed. To detect voltage variation issues, we use the relationship between the power injection and the bus voltages to determine the voltage sensitivity coefficients (VSC) as presented in [28], [41]. Using the Nodal admittance matrix $Y$ that describe the linear power system with $N$ buses, the relationship is expressed as (1)

$$
S_{i}=V_{i} \sum_{j \in N} Y_{i j} V_{j} \quad i \in N
$$

where $V$ is the vector of voltage magnitudes of the nodes $i, j \in\{1, \cdots, K\}, K \bigcup N$. Obtaining the partial derivative of 
the voltages of (1) with respect to the active power $P_{k}$ of a bus $k \in N$ gives

$$
\mathbb{S}_{\{i=k\}}=\frac{\delta V_{i}}{\delta P_{k}} \sum_{j \in N} Y_{i j} V_{j}+V_{i} \sum_{j \in N} Y_{i j} \frac{\delta V_{j}}{\delta P_{k}}
$$

A unique solution exist in (2) to compute the partial derivatives of $\frac{\delta V_{i}}{\delta P_{k}}$ and $\frac{\delta V_{j}}{\delta P_{k}}$. Once they are obtained, the partial derivative of the voltage magnitude can be obtained via

$$
\frac{\delta\left|V_{i}\right|}{\delta P_{k}}=\frac{1}{\left|V_{i}\right|} R e\left(V_{j} \frac{\delta V_{i}}{\delta P_{k}}\right)
$$

Thus, the changes in the bus voltages based on power changes can be determined using (3).

2) Utilisation Rate: line congestion control can be determined through the line utilisation rate. In estimating the line utilisation rate to assign a charge to the prosumer responsible for using the physical network, a power transfer distribution factor (PTDF) is utilised [28]. PTDF captures the variation in power flow at the buses, reflecting power injection at a bus and withdrawal at another bus. Using the derivative of power injection shift factor (ISF) of [28], the PTDF for a branch $(k, l)$ with respect to power injection and withdrawal at nodes $i$ and $j$ is determined through (4)

$$
\phi_{k l}^{i j}=\phi_{k l}^{i}-\phi_{k l}^{j}
$$

where $\phi_{k l}^{i}$ and $\phi_{k l}^{j}$ are the power injections at $i$ and power withdrawal at $j$ for branch $(k, l)$.

3) System Losses: to associate the losses resulting from the bilateral exchange of energy, a bilateral exchange coefficient (BEC) [28], [42] can be used as expressed in

$$
\mathrm{BEC}^{i j}=\frac{\delta P_{\text {loss }}}{\delta P_{i}}-\frac{\delta P_{\text {loss }}}{\delta P_{j}}
$$

where $\frac{\delta P_{\text {loss }}}{\delta P_{i}}$ and $\frac{\delta P_{\text {loss }}}{\delta P_{j}}$ are the loss sensitivities to power injection and withdrawal at $i$ and $j$ respectively defined in (6).

$$
\frac{\delta P_{\text {loss }}}{\delta P_{k}}=2 R E\left[V^{T} G \frac{\delta V}{\delta P_{k}}\right]
$$

Here, $\frac{\delta V}{\delta P_{k}}$ is obtained from (2) and $G$ is the conductance matrix. Equation (6) is termed the loss sensitivity factor (LSF) [43].

Thus, to assess the impact of $\mathrm{P} 2 \mathrm{P}$ energy trading on the distribution network operation, the network constraints defined are used. For instance, using the VSC, any transaction violating the voltage variation will not be allowed to proceed. With PTDF, line utilisation rate can be determined, and subsequent charges assigned to the prosumers using the lines to avoid line congestion. Also, the BEC can calculate the system losses as a result of bilateral exchange, charging the prosumer responsible for the loss. The integration of the constraints is implemented within the trading distance charge discussed in section III-D.

\section{Trading Distance Charge}

Buyers and sellers in the community are grouped based on their location on the feeder as shown in Fig. 2. When a matched buyer and seller are on the same feeder, i.e. feeder A, their transaction proceeds without a distance charge. However, if the buyer and the seller are located on different feeders, i.e., feeders $\mathrm{A}$ and $\mathrm{B}$, their transaction attracts a distance charge. The distance charge is implemented such that the further the transacting prosumers are away from each other, the more the distance charge they pay. A preset multiplier determined by the distance between the feeders is applied to the electricity charge. This multiplier is 1 when buyer and seller are on the same feeder. This will encourage trading between prosumers nearby or the same community and also account for losses that can be incurred during cross feeder transactions. To calculate the distance between a buyer and a seller in two different feeders, we use the Euclidean distance presented in [44] for feeder-to-feeder distance calculation expressed in (7)

$$
d\left(a_{i}, b_{j}\right)=\sqrt{\frac{1}{H} \sum_{h=1}^{H}\left(a_{i h}-b_{j h}\right)^{2}}
$$

where $a_{i}$ and $b_{j}$ represent the buyer on feeder $\mathrm{A}$ and a seller on feeder B respectively. $h \in H$ are the different network constraint features including voltage variations, network utilisation and system losses defined in section III-C that could impact distribution network during energy transaction.

The distance charge between the seller and the buyer is calculated in (8) as,

$$
d_{c h}=1+(d \cdot C)
$$

where $C$ is a constant vector charged per every $\mathrm{kW}$ of transacted energy between the buyer and the seller. An example is demonstrated in Fig. 2, with a cross feeder charge $C$ of $0.002 p / k W h$. If prosumer $i$ on feeder A and prosumer $j$ on feeder B are trading energy with an assumed distance of $500 \mathrm{~m}$ apart, the distance charge will be given as $1+$ $(0.002 \times d(500 m))=2 p / k W h$.

Thus, similar to [28], a third-party entity like DSO validates each matched bid and offer to determine if any network constraint features will be violated. If the constraints will be violated, in case of voltage violation, the trade will not proceed; in case of line utilisation and losses, the charges are incorporated within the distance charge assigned to the trade violating the constraints. This process ensures that energy traders tend to prefer to exchange energy with the closest party to deter excess charge due to network violations resulting from losses and line utilisation.

\section{MARKet Bids And Matching Algorithm}

To develop a P2P-ETS platform, the characteristics of the energy market are first considered. The market has three features: (a) bids are placed at time $t_{0}$ for a trading period $t_{1}$; (b) The trade proceeds after matching participants, and (c) participants are informed about the value of the traded quantity. The market follows pairwise meetings of participants utilising a double auction market where each prosumer plays an active role to provide bids or offers of their demand or supply. 


\section{A. The Trading Period}

In the existing electricity market, energy is bought and sold in a 30 minutes interval. This structure of the market is based on energy generation, consumption, and price that can vary due to [45]:

- Environmental conditions: Since the energy generation focus is on renewable sources, weather conditions affect the generation output of PV panels as well as wind turbines and other renewable sources. A market based on PV panels might increase the trading period during the winter season. Similarly, those based on wind turbines might reduce the trading period during a season with high winds.

- Time of day: The time of electricity usage also affects the market trading period. In the traditional electricity billing, off-peak period usage between $11 \mathrm{pm}$ and $6 \mathrm{am}$ attracts less fee as compared to the peak period, between $4 \mathrm{pm}$ and $9 \mathrm{pm}$, attracting the highest fee [46]. In addition, the time of the day electricity production for PV panels is highest around noon, which calls for a period trading market.

- Grid balancing: The grid must account for the peak and off-peak electricity consumption periods, and the peak and off-peak generation periods within the design of an energy trading market to enable the balancing of supply and demand.

This paper adopts period-based energy trading and a double auction-based market method, with trading executed at $t$ period. Buyers and sellers submit bids (Table II) into the market during each period $t_{0}$ against the next trading period $t_{1}$ for intraday energy delivery. An example of a trading period is shown in Fig. 3.

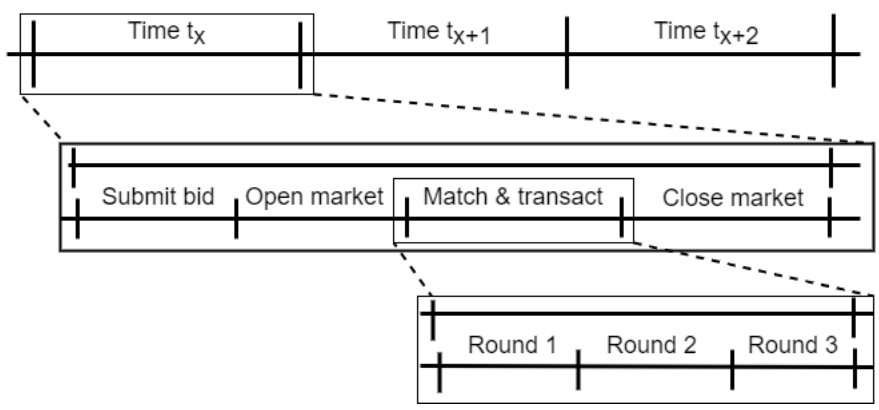

Fig. 3: An illustration of the trading period on the P2P-ETS platform.

The activities at $t_{x}$ are divided into four segments; submit bid, open market, match a transaction, close market including the settlement and market clearing. Once the market is opened for energy trading, no more bids are submitted. The match and transaction activities could proceed to several rounds depending on the number of prosumers and the quantity of demand left in the market before proceeding to settlement and market clearing.

\section{B. The Matching Phase}

The orders submitted to the market are grouped into bids and offer denoted by $N_{\bar{k}}=\left\{1, \cdots, n_{\bar{k}}\right\}$, where $\bar{k}=1,2$, denotes the type of group and type $\bar{k}\left(n_{\bar{k}} \geq 1\right)$. The dual nature of a prosumer of being a consumer or a producer implies that it can take up either of such roles at a given trading period $t_{1}$, submitting either bid or offer at $t_{0}$.

TABLE II: Prosumers' market bid structure

\begin{tabular}{|c|c|c|c|}
\hline Qty. (kWh) & Price (p/kWh) & ID & Role \\
\hline 3.6 & 14.3 & 0 & Bids \\
\hline 1.8 & 12 & 1 & Bids \\
\hline 2 & 14.3 & 2 & Bids \\
\hline 4.2 & 13 & 3 & Bids \\
\hline 10 & 14.3 & 4 & Offer (Grid) \\
\hline 2 & 11 & 5 & Offer \\
\hline 3 & 10 & 6 & Offer \\
\hline 2.5 & 13 & 7 & Offer \\
\hline 4.5 & 10 & 8 & Offer \\
\hline 3 & 9 & 9 & Offer \\
\hline
\end{tabular}

The bid price is the maximum price a consumer is willing to pay for $1 k W h$ of energy, while the offer price is the minimum price a producer is willing to sell $1 k W h$ of energy. For the prosumer to transact, the bid price must be greater than or equal to the offer price. When two prosumers from different groups $N_{1}$ and $N_{2}$ are matched, they trade over the partition or all of the quantity(ies) of energy associated with the match at that period. For instance, at time $t \in T$, let $i \in N_{1}$ and $j \in$ $N_{2}$ be the initially matched prosumers. If their preferences in terms of quantity and price are matched, the prosumers leave the market with the share of the unit price surplus as savings. In the event of unmatched preferences, the algorithm proceeds to the next round (see Fig. 3) where the remaining prosumers in the market are paired with new prosumers until all bids and offers during that trading period are satisfied. However, if any offer remains during the current trading period, the offer is moved to the next open market.

To assess the effect of trading distance, and to evaluate the benefits of local energy consumption, the matching algorithm is evaluated for two scenarios:

1) Matching based on price and quantity: In this scenario, only the price and quantity of energy preference of prosumers are considered in matching the bids and offers. This reference scenario is mostly adopted in the current electricity market system where choice over price and/or source of energy is incorporated.

2) Matching including distance: To evaluate the effect of distance on energy consumption, this scenario incorporated distance charge in the matching phase. As previously discussed that for electricity, transmission losses and other associated costs are largely dependant on the distance travelled making distance an important factor in this work.

\section{Matching and Social Welfare Maximisation}

With a lot of offers and bids to match, the matching is obtained by solving a market clearing optimisation problem to determine the matched peers and their unitary benefits, i.e. to maximise social welfare [47]. Social welfare is the region where any buyer would pay at most what he was willing to pay and any sellers would receive at minimum the price 
he was willing to sell for. In maximising the welfare of all prosumers in the market, a primal-dual gradient method is utilised in [12] using the first-order method. Result in [12] were evaluated against other traditional distributed algorithms including ADMM, interior point methods and centralised approaches proving its efficiency.

Representing the set of consumers $N_{1}$ as $N_{B}$, set of producers $N_{2}$ as $N_{S}$ and set of offers from the prosumers as $\mathcal{L}_{S}=\left\{S_{i}, i=1, \cdots, N_{S}\right\}$, with maximum offer quantity of $Q_{i}^{G}$ at price $P_{i}^{G}$. Similarly, the set of bids from the prosumers is denoted as $\mathcal{L}_{B}=\left\{B_{i}, i=1, \cdots, N_{B}\right\}$, with maximum bid quantity of $Q_{i}^{B}$ at price $P_{i}^{B}$. Thus, the social welfare maximisation problem is expressed as:

$$
\begin{aligned}
\underset{\left\{x_{i}^{S}, x_{i}^{B}\right\}}{\operatorname{maximise}} & {\left[\sum_{i} P_{i}^{B} x_{i}^{B}-\sum_{j} P_{j}^{S} x_{j}^{S}\right] } \\
\text { subject to : } & \sum_{j} x_{j}^{S}-\sum_{i} x_{i}^{B}=0 \\
& 0 \leq x_{i}^{B} \leq Q_{i}^{B}, \quad i=1, \cdots, N_{B} \\
& 0 \leq x_{j}^{S} \leq Q_{j}^{S}, \quad j=1, \cdots, N_{S}
\end{aligned}
$$

Equations (9c) and (9d) are the demand and supply levels to optimise the social welfare of the consumers and producers respectively. The solution $x^{*}$ to solving (9a) as a linear program would only result in a list of matched bids and offers. However, solving (9a) using the dual-Lagrange method gives the complete market clearing. Here, complete market clearing consists of the list of offers (supply and demand, and quantity accepted), achieved through the primal solution and the price at which the market is cleared achieved through the dual solution. Thus, to solve (9a) using the Lagrange multiplier, the following is derived.

$$
\begin{aligned}
& \underset{\lambda^{E},\left\{v_{i}^{B}\right\},\left\{v_{j}^{S}\right\}}{\operatorname{maximise}}\left[-\sum_{j} v_{j}^{S} Q_{j}^{S}-\sum_{i} v_{i}^{B} Q_{i}^{B}\right] \\
& \text { subject to : } \lambda^{E}-v_{j}^{S} \leq P_{j}^{S}, \quad j=1, \cdots, N_{S} \\
& -\lambda^{E}-v_{i}^{B} \leq-P_{i}^{B}, \quad i=1, \cdots, N_{B} \\
& v_{j}^{S} \geq 0, \quad j=1, \cdots, N_{S}, \\
& v_{i}^{B} \geq 0, \quad i=1, \cdots, N_{B}
\end{aligned}
$$

where $\lambda=\lambda^{E}$ is the Lagrange multiplier associated with (9b) representing the equilibrium price and $v=$ $\left[v_{1}^{S}, \cdots, v_{N_{G}}^{S} \quad v_{1}^{B}, \cdots, v_{N_{B}}^{B}\right]^{T}$ is the Lagrange multiplier associated with $(9 \mathrm{c})$ and $(9 \mathrm{~d})$ respectively. The solution $v^{*}$ represents the unitary benefits for the various demand and supply offers when the market is cleared at the equilibrium price $\lambda$. the market mechanism is summarised in Algorithm 1.

\section{Evaluation And Result Analysis}

To assess the performance of the algorithm and VirtElect, the platform development is based on the python programming language. A case of 10 prosumers is first evaluated based on the market bid of Table II. The demand requirement of consumers $0--3$ is based on real energy demand data from the 'PECAN street project' [48]. This dataset is for

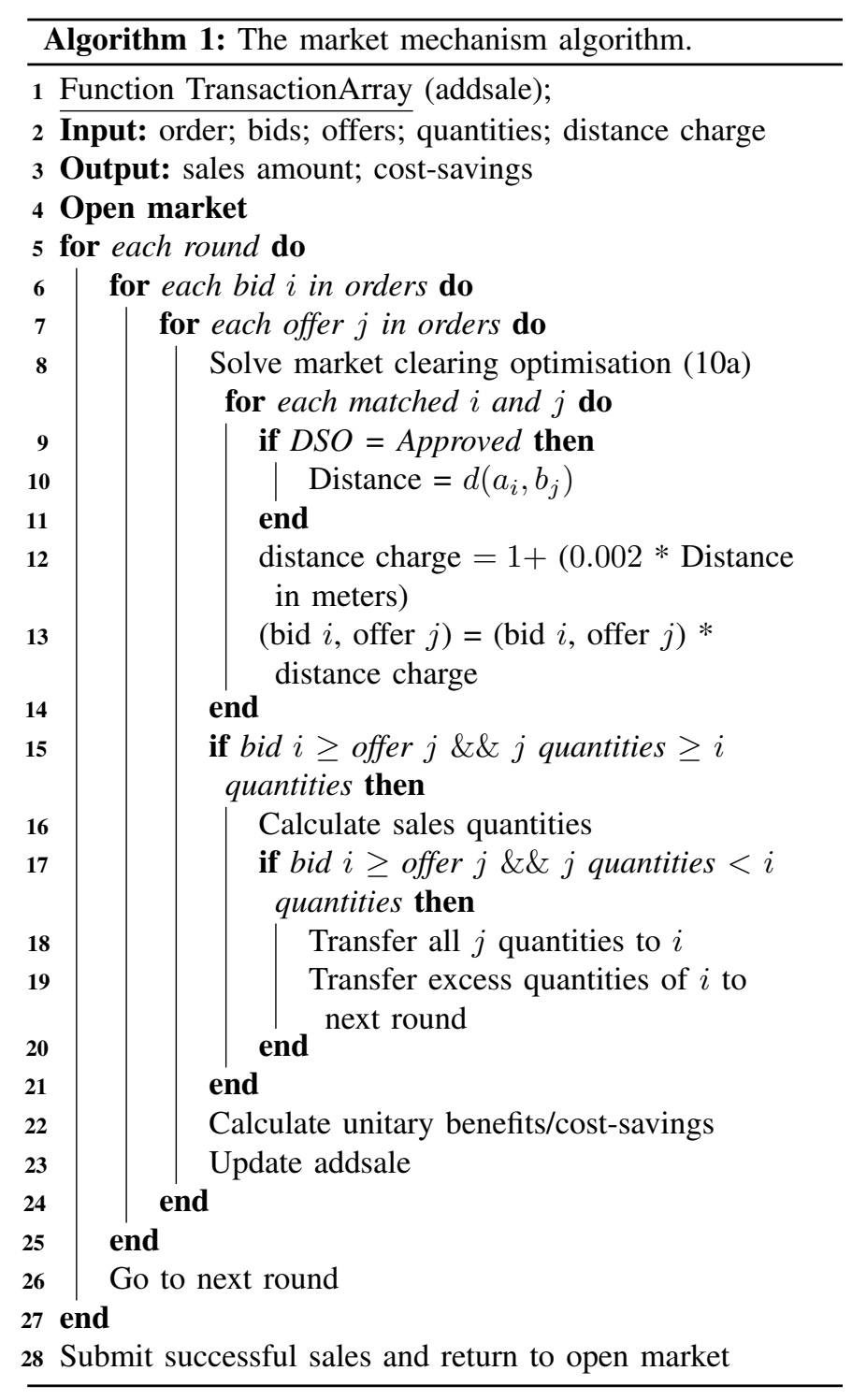

residential households and covers a variety of residential load patterns such as lighting, washing machine, and air conditioning systems, etc., which are used at variable times. As with a realistic power distribution system, the household profiles in the data set vary because the residences' consumption varies. The average peak solar PV output is about $0.4 k W h$, the load demand by residential households will determine which household is willing to buy or sell energy. An instance of the data is presented in Fig. 4.

$P_{\text {load }}$ represents the energy consumption of the house, $P_{\text {grid }}$ is the energy from the grid to balance the consumption, while $P_{\text {solar }}$ is the energy generated over 24 hours by the solar PV panels installed on the household roof. Between the hours of $0: 00--9: 00$, the energy consumption for the household is delivered from the grid. Between the hours of $9: 00--20: 00$, the generated solar energy increased sufficiently so that the household energy is mostly delivered by the solar panels, whilst the energy consumed during the remaining hours of the day is delivered by the grid. The total energy received from the grid is the energy submitted as a 


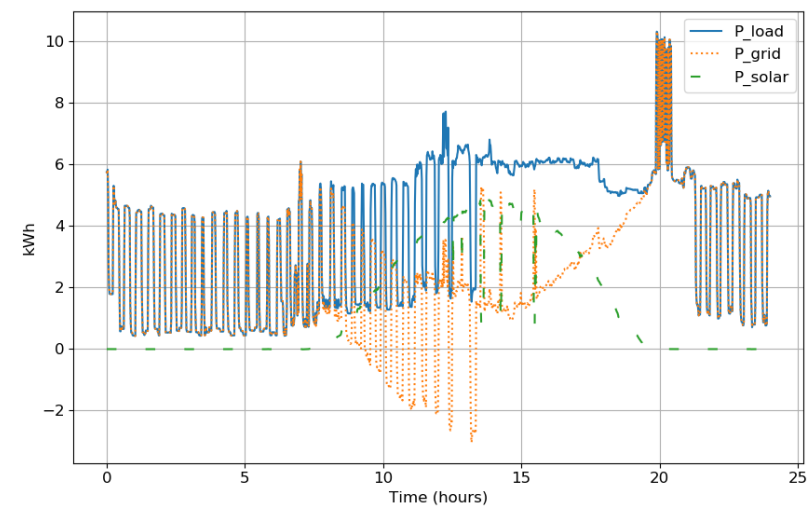

Fig. 4: An instance of a real energy profile of a house used alongside other households in the cases considered.

bid to the market for P2P trade with other prosumers, i.e., consumer 0 profile. In addition, the advertised energy price for the grid is based on the average electricity price for households in the UK.

\section{A. Scenario 1: Matching Based on Price and Quantity of Energy}

This section considers the initial matching of prosumers on the platform based on their bid and offer prices as well as quantity demanded and supplied. The result is analysed based on energy demand and supply, and the cost saved by the prosumers.

1) Energy Demand and Supply on VirtElect: Fig. 5 shows an example of the matched pairs and the amount of energy traded between each pair after a simulation run. It can be observed that due to the divisibility of the demands, some prosumers, i.e., producer 9 , participated in 3 rounds with 3 different paired consumers $(1,3$, and 7$)$.

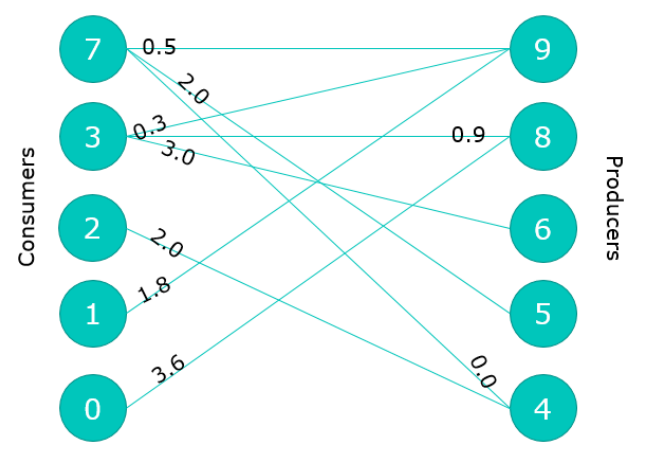

Fig. 5: A graph illustrating the paired prosumers and the amount of energy traded between them.

Fig. 6 shows the result after energy has been traded. In the first round, consumer 0 bought all its quantity demanded from producer 8 , consumer 1 from producer 9 , and consumer 2 from grid 4. Producer 5 sold all its energy surplus to consumer 7 , as producer 6 to consumer 3 . In the second round, the demand requirements of consumer 3 have not been met, thus, consumer 3 is paired with producer 8 . Producer 8 sold all its remaining energy to consumer 3 , while consumer 7 purchased the remaining energy demands from producer 9 . Further, the market interactions proceed to round 3 , where the remaining demand requirements of consumer 3 are met by producer 9 . This shows that all the demands are met by the prosumers on VirtElect.

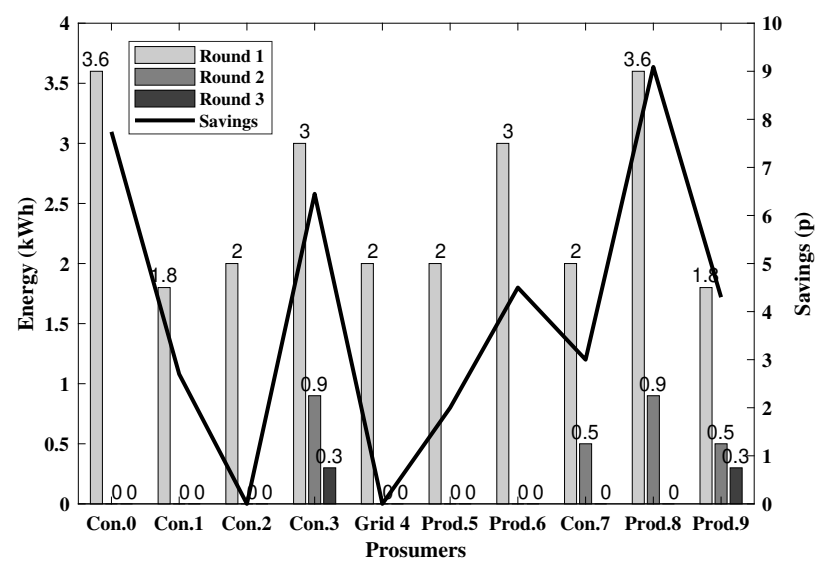

Fig. 6: An illustration of the energy traded between prosumers and individual cost savings.

2) Cost Savings by the Prosumers on VirtElect : The economic benefit in terms of cost savings calculation is based on the price difference of the matched partners that traded energy. For instance, consumer 0's $3.6 \mathrm{kWh}$, with a maximum buy price of $14.3 p / k W h$ is supplied by producer 8 with a minimum sale price of $10 p / k W h$. The difference in the price equals $4.3 p / k W h$, which would be shared as savings for both parties. Thus total savings of consumer 0 by buying $3.6 \mathrm{kWh}$ of energy from the P2P platform is $7.74 p$. This experience relates to other prosumers on VirtElect. However, the maximum and minimum bid and offer price for consumer 2 and grid 4 is $14.3 p / k W h$, thus, both prosumers when paired did not earn any savings. The cost savings is illustrated in Fig. 6 . In addition, it is worth noting that although the grid has the highest amount of energy to sell in the market, it was only able to sell just $2 k W h$ of its $10 k W h$ total energy. This is a result of its minimum offer price, which is higher than most of the consumers' maximum bid price.

\section{B. Scenario 2: Matching Based on Price, Quantity, and Dis- tance}

In this section, the effect of the distance charge is assessed using the segmentation shown in Fig. 2, and mathematical formulations of Section III-D.

The market bid is as shown in Table III, including the location of each prosumer on the distribution feeder. The results are presented based on the energy demanded and supplied as well as the cost saved by the prosumers.

1) Energy Demand and Supply on VirtElect: Fig. 7 shows the result after energy has been traded. In the first round, consumer 0 bought all of its demanded quantity from producer 8 , as consumer 1 from producer 9. Producer 5 sold all its energy surplus to consumer 7 , as producer 6 to consumer 3. Interestingly, consumer 2 was paired with 
TABLE III: Market bid structure and cost savings for Scenario 2.

\begin{tabular}{|c|c|c|c|}
\hline $\begin{array}{c}\text { Prosumer } \\
\text { ID }\end{array}$ & $\begin{array}{c}\text { Dist. C } \\
(\mathrm{p} / \mathrm{kWh})\end{array}$ & $\begin{array}{c}\text { Feeder } \\
\text { Location }\end{array}$ & $\begin{array}{c}\text { Savings } \\
(\mathrm{p})\end{array}$ \\
\hline 0 & 2 & $\mathrm{~A}$ & 15.48 \\
\hline 1 & 4 & $\mathrm{~B}$ & 27.0 \\
\hline 2 & 2 & $\mathrm{~A}$ & 3.71 \\
\hline 3 & 4 & $\mathrm{~B}$ & 62.4 \\
\hline 4 & 6 & $\mathrm{C}$ & 0.0 \\
\hline 5 & 4 & $\mathrm{~B}$ & 8.0 \\
\hline 6 & 2 & $\mathrm{~A}$ & 48.0 \\
\hline 7 & 4 & $\mathrm{~B}$ & 16.5 \\
\hline 8 & 2 & $\mathrm{~A}$ & 29.88 \\
\hline 9 & 2 & $\mathrm{~A}$ & 39.21 \\
\hline
\end{tabular}

grid 4, but no trade occurs between them as the far trading distance resulted in extra charges. In the second round, the demand requirements of consumer 3 were not met, thus, consumer 3 was paired with producer 8 . Producer 8 sold all its remaining energy to consumer 3 , while consumer 2's demand requirements were met by producer 9 . Grid 4 was paired with consumer 7 , but no trade occurred between them as the far trading distance resulted in extra charges. Further, the market interaction proceeds to round 3 , where the remaining demand requirements of consumer 7 were met by producer 9 .

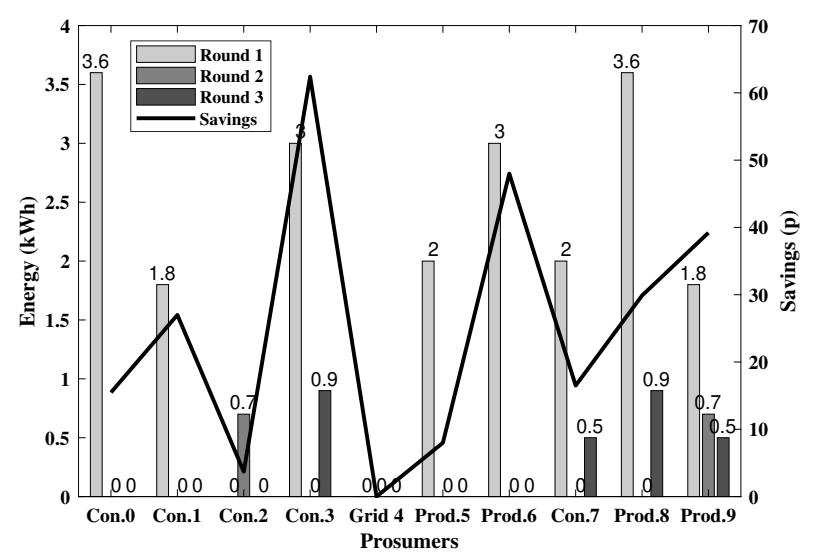

Fig. 7: An illustration of the energy traded between pairs and individual cost savings.

2) Cost Savings by the Prosumers on VirtElect: Similarly, using the cost savings calculations described in Section V-A2, the economic benefit in terms of cost savings of consumer 0 by buying $3.6 \mathrm{kWh}$ of energy from producer 8 on VirtElect is $15.48 p$. The cost savings for other prosumers are shown in Table III and Fig. 7. However, the maximum and minimum bid and offer price for consumer 2 and grid 4 is $14.3 p / k W h$, but because they are located at different feeders when the two were paired, no trade occurs. In addition, the grid was paired with consumer 7 in the second round, however, no trade occurs between them. Thus, the grid earned $0 p$ savings in this scenario. It can be observed that while consumer 2 did not earn any savings in the first scenario because of the paired partner (grid), he earned a total savings of $3.71 p$ in this scenario, as a result of declining the grid offer and subsequently being paired with a producer with a lower asking price. These results show that consumers of local energy consumption acquired more cost savings than prosumers that do not trade energy locally.

3) Environmental Impact Analysis: While energy generated from renewable is universally regarded as green energy, energy transmission between consumer and producer might also result in emission losses depending on their distance. This is called transmission and distribution losses. To evaluate the environmental benefit of P2P-ETS, we calculate the total emissions equivalent to generating and consuming energy locally using (11)

$$
\mathrm{CO}_{2} \text { emissions }=\text { activity data } \times \text { emission factor }
$$

The emissions factor calculated by BEIS for electricity generated is $0.23314 \mathrm{kgCO}_{2} \mathrm{e}$, while for transmission and distribution losses is $0.02005 \mathrm{kgCO}_{2} \mathrm{e}$ for the year 2020 [49]. The activity data is the equivalent of electricity consumption and supply in this case. We evaluate the environmental benefit of local energy generation and consumption in the case study given in Table II. The total generation and demand in Table II is $36.6 \mathrm{kWh}$ resulting in a $\mathrm{CO}_{2}$ emissions reduction of 9.2668 $\mathrm{kgCO}_{2}$ e. $92 \%$ of the reduced emissions are accustomed to local energy generation and consumption. Factoring transmission distance into the study saves $8 \%$ of $\mathrm{CO}_{2}$ emissions.

\section{Scenario 3: Impact of Ratio of Producers to Consumers on VirtElect and Scalability Assessment}

Additional assessment is carried out to evaluate the performance and scalability of VirtElect to varying ratios of producers/sellers to consumers/buyers. A range of representative values of demands, supplies, and prices are assigned to the prosumers. For the buyers, the minimum offer price is set between $11-14 p / k W h$, the quantity of energy demand is set to $1-5 k W h$, while the sellers' bid price is set to $10-15 p / k W h$ and the quantity of energy supplies is set to $5-10 k W h$. Simulations were run for a different ratio of sellers to buyers for 30 participants. Fig. 8 shows the relationship between the total supply, demand, and cost savings against varying ratios of prosumers.
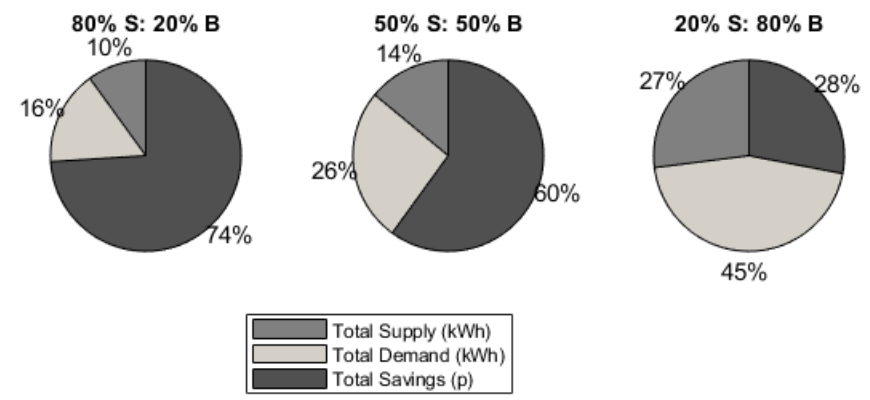

Fig. 8: A pie chart showing the relationship between the total supply, demand, and savings for a different ratio of sellers to buyers.

It can be observed that with a ratio of $80 \%$ of sellers to $20 \%$ of buyers, the total supply increased with less demand, compared to when there are $20 \%$ of sellers on the platform, 
as the total cost savings are a reflection of the volume of trade that occurs on the VirtElect. With $80 \%$ sellers, the savings is $16 \%$ compared to $20 \%$ sellers and $45 \%$ cost savings. This result emphasises the importance of a P2P exchange of energy, the more the local demand is met by the local supply, the higher the community cost savings.

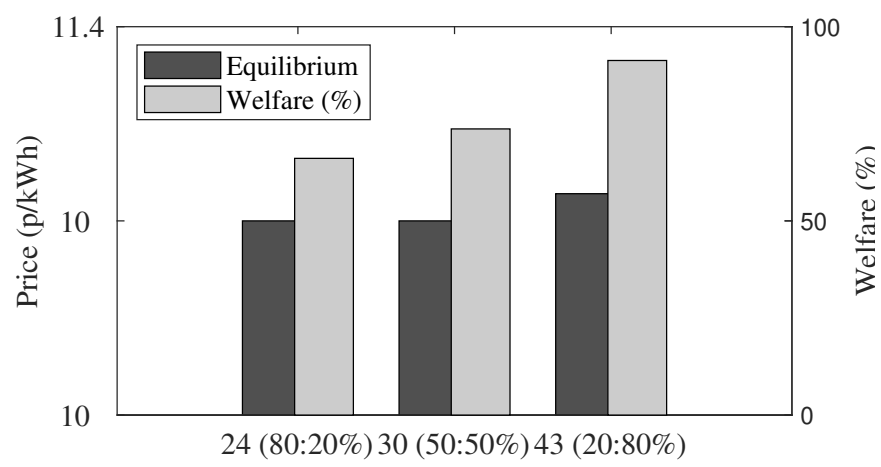

Fig. 9: Relationship between the equilibrium price, quantity, and the percentage welfare for a different ratio of prosumers.

Similarly, Fig. 9 shows the relationship between the equilibrium price, quantity, and the percentage of the maximum welfare against the ratio of prosumers on the platform. It can be observed that for $80 \%$ of sellers, the average quantity traded is $24 k W h$ at an equilibrium price of $10 p / k W h$. However, with $50 \%$ of sellers, the traded quantity increased to $30 \mathrm{kWh}$ which reflects the increase in demand due to the increased number of buyers. In addition, with more buyers on the platform, $80 \%$, the traded quantity, and the equilibrium price increased to $43 k W h$ and $11 p / k W h$ respectively. This reflects an economic market where an increase in demand and a decrease in supply leads to an increase in the price of the commodity. In addition, it can be observed from the plot that the percentage welfare of the participants increases as the ratio of buyers increases on the platform.

To further demonstrate the scalability of the energy market, Fig. 10 and Fig. 11 show a particular run for 100 participants.

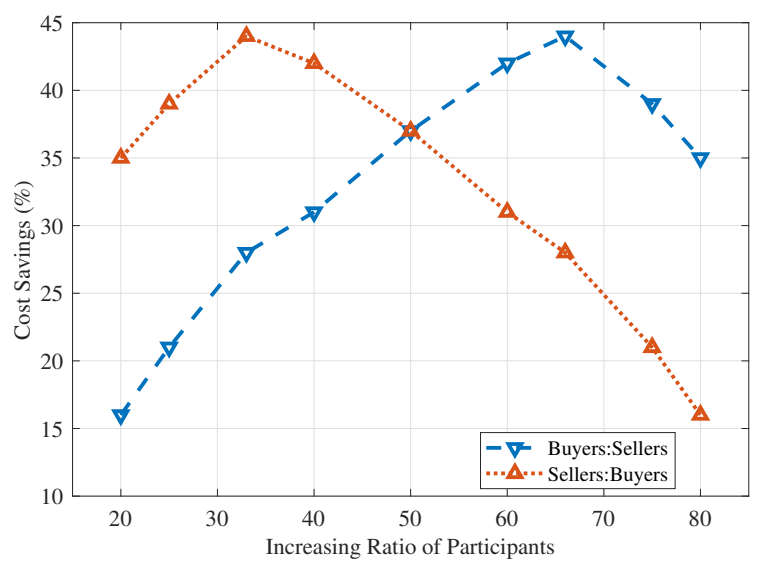

Fig. 10: Impact of different ratios of prosumers to total cost savings.

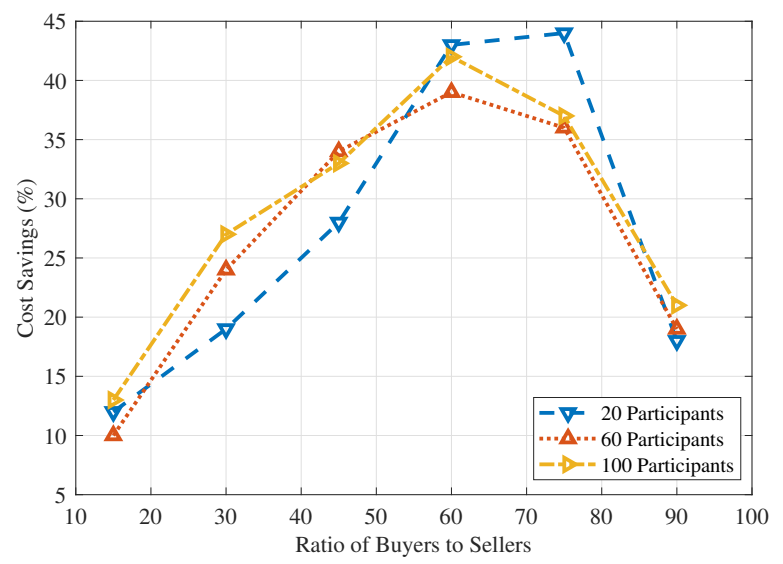

Fig. 11: Impact of different ratios of buyers to sellers for an increasing number of participants and total cost savings.

In Fig. 10, as the ratio of buyers increases against the ratio of sellers, the cost savings increase. However, when the ratio of buyers to sellers exceeds $66 \%$, a decline in cost savings is observed. Similarly, when the ratio of buyers to sellers exceeds $33 \%$, a decline in cost savings was also observed. These results further suggest that the role of prosumers on VirtElect determines the cost savings. Such as fewer savings when there are more sellers than buyers and vice versa. Finally, when utilising the ratio of buyers to sellers for an increasing number of participants, Fig. 11 shows an increase in cost savings. This savings reflect when the buyer to seller ratio ranges between $0 \%$ to $60 \%$ and declines when the ratio exceeds $60 \%$. This suggests that as the number of prosumers increases, local demands are met, and cost savings increase. However, these cost savings could decline with a disproportionate number of consumers to producers.

To sum, VirtElect can easily be implemented and managed. It has been demonstrated that it is economical for consumers and prosumers in a decentralised energy paradigm where the exchange of energy can be dynamically negotiated to fit individual needs. Thus, reducing the dependency of the central grid and enabling a more competitive environment. This will incentivise further participation in the trading and sharing of locally generated energy. Similarly, the economic benefit to the DSO is realised by balancing local energy generation and consumption through trading. This would assist the grid during peak demand and deter the deployment of generators or high infrastructure to balance and stabilise the system, thus, reducing investment costs.

\section{CONCLUSION AND FUtURE WORK}

This paper presented the design and implementation of a P2P-ETS platform - VirtElect for local energy consumption and trading. The paper commenced with a description of the platform design that highlighted the interaction between prosumers. Then, the market mechanism used on the platform was discussed for the two used cases considered giving a snapshot of the developed platform interface in the appendix. Simulation results indicate that local energy trading is not only 
beneficial to the environment but also leads to a significant amount of savings by the trading prosumers of up to $45 \%$, depending upon their number and ratio on the platform. Future work will include testing the performance of the platform and market mechanism incorporating more prosumers and functions that will consider more matching resources, preferences and objectives over an extended period. In addition, future work will explore the use of distributed ledger technology to develop smart contracts that can be used to manage trust and transactions on VirtElect.

\section{APPENDIX}

\section{VirtElect INTERFACE}

This section shows the interface of the developed P2P-ETS platform as shown in Figs. 12, 13, 14, and Fig. 15.

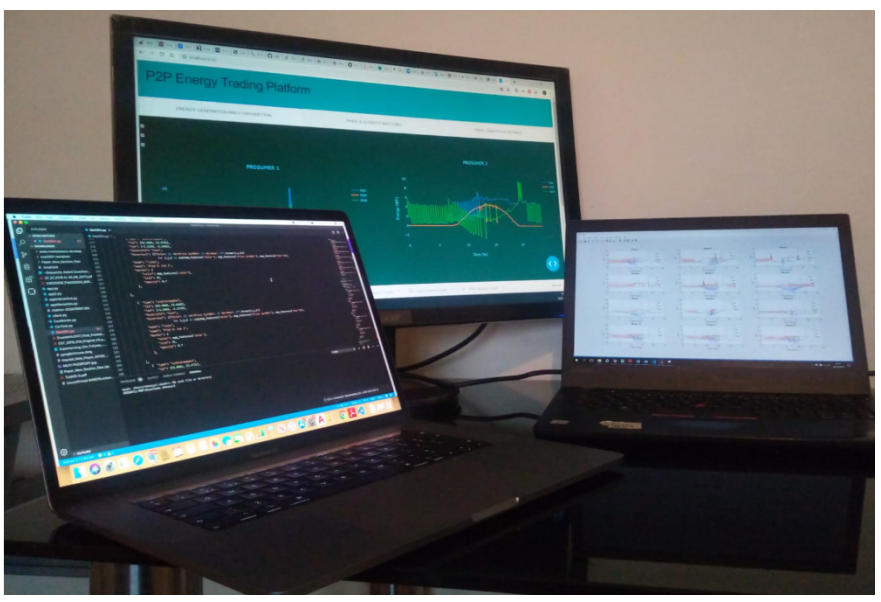

Fig. 12: P2P-ETS platform set-up with connected devices.

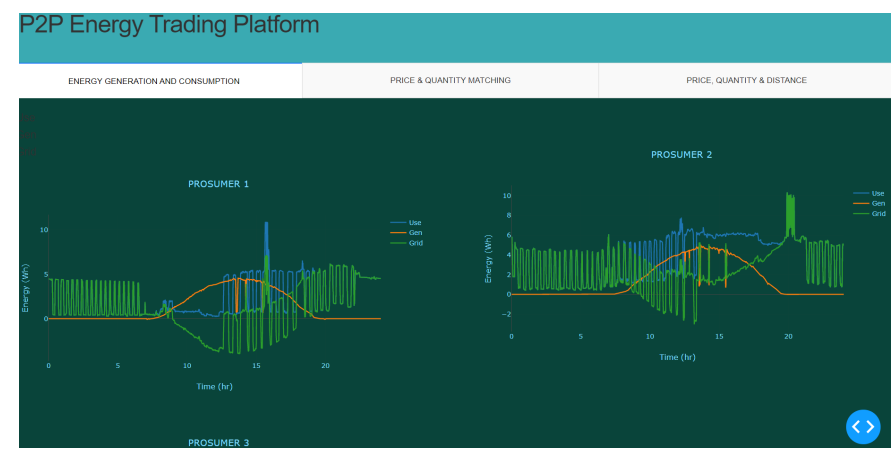

Fig. 13: Prosumers profiling on the P2P-ETS platform.

Fig. 12 shows the overall setup of the connected devices representing prosumer smart meters on the P2P-ETS platform. Fig. 13 shows the received energy profile of the prosumers. This shows details of the energy generated, consumed, and received from the grid as represented in Fig. 4. Similarly, Fig. 14 shows the bid submitted to the market and the location of the market participants. The submitted bid is as represented in Tables II and III and the plot as shown in Fig. 7. Fig. 14 shows the energy transfer between those that trade, as well as the links connecting them on the map.

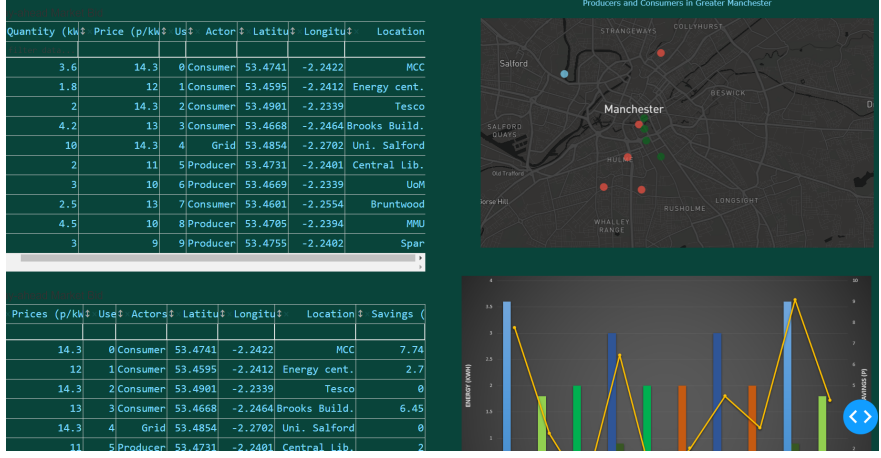

Fig. 14: Market bid and the prosumers' location on the P2PETS platform.

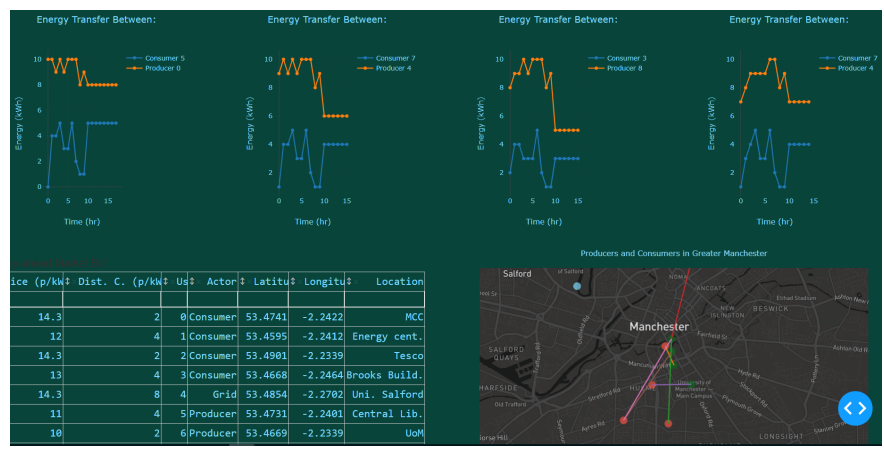

Fig. 15: Energy transfer between prosumers and links connecting trading pairs.

\section{REFERENCES}

[1] C. Zhang, J. Wu, Y. Zhou, M. Cheng, and C. Long, "Peer-to-peer energy trading in a microgrid," Appl. Energy, vol. 220, pp. 1-12, 2018.

[2] O. Jogunola, W. Wang, and B. Adebisi, "Prosumers matching and leastcost energy path optimisation for peer-to-peer energy trading," IEEE Access, vol. 8, pp. 95 266-95 277, 2020.

[3] G. Sun, F. Zhang, D. Liao, H. Yu, X. Du, and M. Guizani, "Optimal energy trading for plug-in hybrid electric vehicles based on fog computing," IEEE Internet of Things J., vol. 6, no. 2, pp. 2309-2324, 2019.

[4] Open-Utility, "Building a smarter energy future," 2020, accessed: 2021-06-26. [Online]. Available: https://piclo.energy/about

[5] Vandebron, "Green energy, good price, no hassle," 2021, accessed: 2021-06-26. [Online]. Available: http://www.vandebron.nl/

[6] SonnenCommunity, "It's time to declare your independence," 2021, accessed: 2021-06-26. [Online]. Available: http://www.sonnenbatterie.de/en/sonnenCommunity/

[7] Brooklynmicrogrid, "Brooklyn microgrid," 2015, accessed: 2020-06-26. [Online]. Available: http://brooklynmicrogrid.com/

[8] T. Morstyn, N. Farrell, S. J. Darby, and M. D. McCulloch, "Using peer-to-peer energy-trading platforms to incentivize prosumers to form federated power plants," Nature Energy, vol. 3, no. 2, pp. 94-101, 2018.

[9] E. Mengelkamp, B. Notheisen, C. Beer, D. Dauer, and C. Weinhardt, "A blockchain-based smart grid: towards sustainable local energy markets," Computer Sci.-Research and Dev., vol. 33, no. 1-2, pp. 207-214, 2018.

[10] O. Jogunola, A. Ikpehai, K. Anoh, B. Adebisi, M. Hammoudeh, S.Y. Son, and G. Harris, "State-of-the-art and prospects for peer-to-peer transaction-based energy system," Energies, vol. 10, no. 12, p. 2106, 2017.

[11] ofgem, "Breakdown of an electricity bill," 2020, accessed: 2020-10-15. [Online]. Available: https://www.ofgem.gov.uk/data-portal/breakdownelectricity-bill

[12] M. Khorasany, Y. Mishra, and G. Ledwich, "A decentralized bilateral energy trading system for peer-to-peer electricity markets," IEEE Trans. Ind. Electron., vol. 67, no. 6, pp. 4646-4657, 2020.

[13] O. Jogunola, M. Hammoudeh, K. Anoh, and B. Adebisi, "Distributed ledger technologies for peer-to-peer energy trading," in Proc. IEEE Electric Power and Energy Conf., 2020, pp. 1-6. 
[14] O. Jogunola, B. Adebisi, A. Ikpehai, S. I. Popoola, G. Gui, H. Gacanin, and $\mathrm{S}$. Ci, "Consensus algorithms and deep reinforcement learning in energy market: A review," IEEE Internet of Things J., vol. 8, no. 6, pp. 4211-4227, 2021

[15] S. Chakraborty, T. Baarslag, and M. Kaisers, "Automated peer-to-peer negotiation for energy contract settlements in residential cooperatives," Appl. Energy, vol. 259, p. 114173, 2020

[16] F. Moret, T. Baroche, E. Sorin, and P. Pinson, "Negotiation algorithms for peer-to-peer electricity markets: Computational properties," in Proc. IEEE Power Syst. Comput. Conf., 2018, pp. 1-7.

[17] A. Amato, R. Aversa, B. Di Martino, M. Scialdone, S. Venticinque, S. Hallsteinsen, and G. Horn, "Software agents for collaborating smart solar-powered micro-grids," in Smart Org. and Smart Artifacts. Springer, 2014, pp. 125-133.

[18] O. Jogunola, B. Adebisi, K. Anoh, A. Ikpehai, M. Hammoudeh, and G. Harris, "Multi-commodity optimisation of peer-to-peer energy trading resources in smart grid," J. Modern Power Syst. and Clean Energy, 2021.

[19] M. R. Alam, M. St-Hilaire, and T. Kunz, "An optimal p2p energy trading model for smart homes in the smart grid," Energy Efficiency, vol. 10, no. 6, pp. 1475-1493, 2017.

[20] E. Sorin, L. Bobo, and P. Pinson, "Consensus-based approach to peerto-peer electricity markets with product differentiation," IEEE Trans. Power Systems, vol. 34, no. 2, pp. 994-1004, 2019.

[21] F. Moret and P. Pinson, "Energy collectives: a community and fairness based approach to future electricity markets," IEEE Trans. Power Syst., vol. 34, no. 5, pp. 3994-4004, 2018.

[22] X. Lu, X. Xiao, L. Xiao, C. Dai, M. Peng, and H. V. Poor, "Reinforcement learning-based microgrid energy trading with a reduced power plant schedule," IEEE Internet of Things J., vol. 6, no. 6, pp. 10728 10737, 2019.

[23] J. Kang, R. Yu, X. Huang, S. Maharjan, Y. Zhang, and E. Hossain, "Enabling localized peer-to-peer electricity trading among plug-in hybrid electric vehicles using consortium blockchains," IEEE Trans. Ind. Info., vol. 13, no. 6, pp. 3154-3164, 2017.

[24] K. Chen, J. Lin, and Y. Song, "Trading strategy optimization for a prosumer in continuous double auction-based peer-to-peer market: A prediction-integration model," Appl. energy, vol. 242, pp. 1121-1133, 2019.

[25] W. Liu, D. Qi, and F. Wen, "Intraday residential demand response scheme based on peer-to-peer energy trading," IEEE Trans. Ind. Info., vol. 16, no. 3, pp. 1823-1835, 2019.

[26] J. Wang, H. Zhong, C. Wu, E. Du, Q. Xia, and C. Kang, "Incentivizing distributed energy resource aggregation in energy and capacity markets: An energy sharing scheme and mechanism design," Appl. Energy, vol. 252, p. 113471, 2019.

[27] B. P. Hayes, S. Thakur, and J. G. Breslin, "Co-simulation of electricity distribution networks and peer to peer energy trading platforms," Intl. J. Elect. Power \& Energy Syst., vol. 115, p. 105419, 2020.

[28] J. Guerrero, A. C. Chapman, and G. Verbič, "Decentralized p2p energy trading under network constraints in a low-voltage network," IEEE Trans. Smart Grid, vol. 10, no. 5, pp. 5163-5173, 2019.

[29] C. Etukudor, B. Couraud, V. Robu, W.-G. Früh, D. Flynn, and C. Okereke, "Automated negotiation for peer-to-peer electricity trading in local energy markets," Energies, vol. 13, no. 4, p. 920, 2020.

[30] J. Guerrero, B. Sok, A. C. Chapman, and G. Verbič, "Electrical-distance driven peer-to-peer energy trading in a low-voltage network," Appl. Energy, vol. 287, p. 116598, 2021.

[31] T. Baroche, P. Pinson, R. L. G. Latimier, and H. B. Ahmed, "Exogenous cost allocation in peer-to-peer electricity markets," IEEE Trans. Power Syst., vol. 34, no. 4, pp. 2553-2564, 2019.

[32] M. Khorasany, Y. Mishra, and G. Ledwich, "Hybrid trading scheme for peer-to-peer energy trading in transactive energy markets," IET Gen., Trans. \& Dist., vol. 14, no. 2, pp. 245-253, 2020.

[33] M. H. Ullah and J.-D. Park, "Peer-to-peer energy trading in transactive markets considering physical network constraints," IEEE Trans. Smart Grid, vol. 12, no. 4, pp. 3390-3403, 2021.

[34] J. Mei, C. Chen, J. Wang, and J. L. Kirtley, "Coalitional game theory based local power exchange algorithm for networked microgrids," Appl. energy, vol. 239, pp. 133-141, 2019.

[35] R. Khalid, N. Javaid, A. Almogren, M. U. Javed, S. Javaid, and M. Zuair, "A blockchain-based load balancing in decentralized hybrid p2p energy trading market in smart grid," IEEE Access, vol. 8, pp. 47047-47062, 2020.

[36] E. Elliott, N. Shanklin, S. Zehtabian, Q. Zhou, and D. Turgut, "Peerto-peer energy trading and grid impact studies in smart communities," in Proc. IEEE Intl. Conf. Comput., Network. and Commun., 2020, pp. 674-678.
[37] E. Münsing, J. Mather, and S. Moura, "Blockchains for decentralized optimization of energy resources in microgrid networks," in Proc. IEEE Conf. Control Tech. and App., 2017, pp. 2164-2171.

[38] T. Morstyn and M. D. McCulloch, "Multiclass energy management for peer-to-peer energy trading driven by prosumer preferences," IEEE Trans. Power Syst., vol. 34, no. 5, pp. 4005-4014, 2018.

[39] J. Hu, G. Yang, H. W. Bindner, and Y. Xue, "Application of networkconstrained transactive control to electric vehicle charging for secure grid operation," IEEE Trans. Sust. Energy, vol. 8, no. 2, pp. 505-515, 2016.

[40] E. Reihani, P. Siano, and M. Genova, "A new method for peer-to-peer energy exchange in distribution grids," Energies, vol. 13, no. 4, p. 799, 2020.

[41] K. Christakou, J.-Y. LeBoudec, M. Paolone, and D.-C. Tomozei, "Efficient computation of sensitivity coefficients of node voltages and line currents in unbalanced radial electrical distribution networks," IEEE Trans. Smart Grid, vol. 4, no. 2, pp. 741-750, 2013.

[42] F. D. Galiana, A. J. Conejo, and H. A. Gil, "Transmission network cost allocation based on equivalent bilateral exchanges," IEEE Trans. Power Syst., vol. 18, no. 4, pp. 1425-1431, 2003.

[43] A. J. Conejo, F. D. Galiana, and I. Kockar, "Z-bus loss allocation," IEEE Trans. Power Syst., vol. 16, no. 1, pp. 105-110, 2001.

[44] V. Rigoni, L. F. Ochoa, G. Chicco, A. Navarro-Espinosa, and T. Gozel, "Representative residential lv feeders: A case study for the north west of england," IEEE Trans. Power Syst., vol. 31, no. 1, pp. 348-360, 2015.

[45] J. Park, R. Chitchyan, A. Angelopoulou, and J. Murkin, "A block-free distributed ledger for $\mathrm{p} 2 \mathrm{p}$ energy trading: Case with iota?" in Proc. Intl. Conf. Advanced Info. Syst. Eng., 2019, pp. 111-125.

[46] T. Telegraph, "New electricity tariff offers 80pc discount for night-time usage," 2017, accessed: 2020-07-26. [Online]. Available: https://www.telegraph.co.uk/bills-and-utilities/gaselectric/new-electricity-tariff-offers-80pc-discount-night-time-usage/

[47] H. S. Esch, F. Moret, P. Pinson, and A. M. Radoszynski, "Online matching and preferences in future electricity markets," in Proc. 19th Yale Workshop on Adaptive and Learning Syst., 2019, pp. 1-9.

[48] F. M. Uriarte, "Pecan street project field data," 2014, accessed: 2019-05-06. [Online]. Available: https://sites.google.com/site/fabianuriarte/downloads

[49] BEIS, "Greenhouse gas reporting: conversion factors 2020," 2020, accessed: 2021-03-26. [Online] Available: https://www.gov.uk/government/publications/greenhouse-gasreporting-conversion-factors-2020 